\title{
Is Epistemic Permissivism a Consistent Position to Argue from?
}

\author{
Matthew Wilson
}

Baylor University

Epistemic permissivism ("EP") is the view that, sometimes, it is possible for two people to rationally adopt different doxastic attitudes towards a proposition given the same body of evidence. In other words, epistemic permissivists ("EPists") maintain that it is possible for $\mathrm{S}$ to rationally believe that $p$, and $S^{*}$ to rationally believe that $\sim p$, even though they both have the same evidence rel evant to $p^{1}{ }^{1} \mathrm{E}$ Pists thus deny rational uniqueness. UNIQUENESS is the view that there is one unique doxastic attitude a person may rationally take towards a proposition, given one's total body of evidence. ${ }^{2}$ In cases where two people adopt opposing attitudes toward a proposition given the same body of evidence, UNIQUENESS claims at most one of their attitudes can be fully rational.

Numerous arguments have been advanced both for epistemic permissivism (Schoenfield, 2014; Brueckner and Bundy, 2012; Douven, 2009; Rosen, 2006, 2001; van Fraassen, 2002) and against it (M atheson, 2011; Sosa, 2010; Feldman, 2009, 2007; Christensen, 2010; W hite, 2005), but neither side seems convinced. This makes one wonder whether $E P$, as an epistemological thesis, is itself is a permissive case or whether one side is simply holding a view that is not rational. Of course the answer to such a question will depend on which side of the debate one is on. In this paper I argue that the question of whether the entire EP/ UNIQUENESS debate (hereafter, "EP debate") is a permissive case - one where both sides are rationally holding opposing views - is a question that EPists must answer. I provide reasons to think that EPists should consider the EP debate to be a permissive case. If I am right in this, however, then EPists have an internal tension in their view that defenders of UNIQUENESS do not have. Namely, if EP itself is a permissive case, then EPists should not wish to argue that defenders of UNIQUENESS give up their views since they are rationally holding them. That is unless EPists are able to put forth some sort of new relevant evidence.

In Section I, I explore what it means to be a permissive case and argue that EPists should consider the EP debate to be a permissive one. In section II, I lay out and defend an argument which shows that, if EPists do take the EP debate to be a permissive case, then unless they have new evidence to contribute to the debate, they should not wish to convince defenders of 
UNIQUENESS to give up their views. In Section III, I answer a possible objection to the argument laid out in Section II.

\section{Is Permissivism Permissive?}

Defenders of permissivism argue that two subjects may rationally adopt different doxastic attitudes towards a proposition because each subject may approach the same hypothesis with different, yet rational, sets of epistemic standards. The differences in these standards mean that the same evidence may be interpreted (or weighed) in different ways. Thus, EPists claim that EP may be one way to explain apparent cases of rational disagreement. B ut EPists usually do not think that EP always holds true; it only holds true in permissive cases. These so-called permissive cases are usually ones that involve a complex body of evidence. A permissive case can be defined as follows:

Permissive Case: a case in which S's total evidence makes it rational to believe $p$ and also makes it rational to believe $\sim p$.

The question this paper raises is whether EP, as an epistemological thesis, should be considered a permissive case. Of course, this question can only be meaningfully asked from an EPist's point of view. Since defenders of UNIQUENESS deny that there are permissive cases at all, they would al so deny that the EP debate could be permissive. But what should an EPist say about EP, considered as a hypothesis? Is it permissive? The answer has important implications for the view. In what follows I will provide reasons to think that EPists should consider EP to be a permissive case. But before proceeding, let's formulate this as a premise:

\section{(1) EPists should think that EP itself is a permissive case.}

In order for EP to be a permissive case, two conditions must hold. First, it must be possible for disagreeing parties to have the same body of evidence $E$ with respect to $E P$. Second, it must be possible, given $E$, for one party to rationally believe EP and the other to rationally believe $\sim E P .^{3}$

Why suppose that the philosophers in this debate have the same body of evidence? First, EPists deny that all or even most cases of disagreement should be attributed to subjects having differing bodies of evidence (See, for example, Rosen 2001:71; Schoenfield 2014: 196-197). Otherwise nearly all disagreement could be explained by way of appeal 
to these differing evidential sets. EPists presume that that permissive cases are fairly common and applicable to a wide range of subject matter. If permissive cases were extremely rare, EP as a theory would be much less interesting. Example cases EPists take to be permissive include: jury members disagreeing over the guilt of a defendant (Schoenfield, 2014; Brueckner and Bundy, 2012; Rosen, 2001); paleontologists disagreeing over what killed the dinosaurs (Schoenfield, 2014; Rosen, 2001); and philosophers disagreeing over whether there is an analytic/synthetic distinction (Schoenfield, 2014). In each of these cases, the evidential sets of jury members, paleontologists and philosophers are, respectively, presumed to be the same. The disagreements that arise in these examples are thought to be because people are interpreting (or weighing) the same evidence using different sets of rational epistemic standards. EPists deny that these disagreements should usually be attributed to subjects having different bodies of evidence.

W hat about the EP debate? This case presents strong similarities to the examples cited above. Philosophers who disagree in the EP debate are well-informed and possess the same body of specialized knowledge. They are aware of the evidence and arguments made for each view. It seems, then, by parity of reasoning with respect to these other cases, EPists ought to think that philosophers engaged in this debate have the same body of evidence. ${ }^{4}$ Denying that defenders of UNIQUENESS have the same evidence would call into question EPists own assumptions regarding what counts as evidential differences in these other cases (which notably, are supposed to be evidence for EP!) EPists therefore have reason not to restrict the notion of "having the same body of evidence" too narrowly.

If philosophers in this debate do have the same evidence, EPists must next ask whether it is possible to rationally interpret this evidence differently. A ccording to the spirit of their own view, the answer seems to be yes: it should be rational to accept UNIQUENESS. This conclusion is plausible because of the resemblance that the EP debate has to the other examples EPists presume to be permissive. It would be strange for an EPist to think, given the spirit of their arguments, that entire groups of philosophers are being irrational in holding UNIQUENESS. This would seem suspicious. Of course there is nothing that logically prevents EPists from saying this, but then there is a burden of proof to show why the EP debate is so different.

From the above considerations, EPists have good reason to consider the EP debate to be such that the disagreeing parties have the same evidence and yet rationally disagree. There is reason for EPists to presume the disagreement is caused by different, yet rational, epistemic standards. 
EPists therefore have good reason to think that EP itself is a permissive case. $^{5}$

\section{Tensions in the View}

If the EP debate is permissive and U NIQUENESS is a rational view to hold, it should be understandable to EPists why defenders of UNIQUENESS reject EP and wish to argue against it. From a UNIQUENESS theorist's perspective, it is not permissible to believe EP; they see EP as an irrational position to hold. ${ }^{6}$ We can see this as follows:

(1) EPists should think that the EP debate itself is a permissive case.

(2) If the EP debate is a permissive case, then UNIQUENESS ( EP) is a rational epistemic standard.

(3) UNIQUENESS is therefore a rational epistemic standard. (modus ponens 1, 2)

(4) If UNIQUENESS is a rational epistemic standard, then it is rational for defenders of UNIQUENESS to reject EP as an irrational view to hold.

By (3) and (4), it is clear why defenders of UNIQUENESS wish to convince EPists to give up their views. They rationally believe EP is irrational. However, things look different from the EPists' perspective. There is an internal tension (or inconsistency) with their desire to convince defenders of UNIQUENESS to give up U NIQUENESS. This can be seen as follows:

(5) EPists wish to argue that defenders of UNIQUENESS should give up UNIQUENESS.

(6) If an EPist wishes to argue that a defender of UNIQUENESS should give up UNIQUENESS, then an EPist should either

(i) point to some further evidence that makes it clear why UNIQUENSS is false,

or

(ii) show them that that UNIQUENESS is a non-rational epistemic standard.

(7) But if (i), then EPists should not think the EP debate itself is a permissive case. (contradiction $1,6 . i$ )

(8) A nd if (ii), then EPists should not think U NIQ UENESS is a rational epistemic standard. (contradiction 3, 6.ii)

(9)T Therefore, EPists should not rationally wish to argue that defenders of UNIQUENESS should give up UNIQUENESS. (reductio 1-8) 
This conclusion seems like an undesirable result for EPists. Let's examine premises (5)-(8) and see why one might accept them. Premise (5) seems to be obvious. Philosophers writing on the issue of EP claim that UNIQUENESS is false, and the fact that they are writing to convince others of its falsity suggests that they think defenders of UNIQUENESS should give up their view. Premise (6) needs defense. It relies on an intuition of why a person should rationally want to convince someone else that a belief they hold is false. The intuition is a norm of rational discourse, and it goes something like this. $\mathbf{S}$ should only want to attempt to convince $S^{*}$ of the falsity of her belief if $S$ can provide reasons for why $S^{*}$ 's view is false. If one cannot provide reasons for why a belief is false, then one should abstain from arguing. M oreover, if reasons cannot be provided, then there seems to be no good rational reason to want to change the other's view. Even if I prefer my own view and think it is true, I should not rationally want to change another's opinion if I cannot give them any reasons why their view is false. M erely preferring my own view is not a sufficient ground to wish to convince another in the context of rational discourse. A proper reason to wish to convince another may come in one of two forms, which are formulated in (6.i) and (6.ii) above. One's interlocutors may not have considered all of the available evidence pertinent to the hypothesis in question, and this evidence might be provided as a reason for them to change their belief. Or one's interlocutors may be using epistemic standards that are not rational. However, I have already argued that EPists should think each party in the debate possesses the same body of evidence and a rational set of epistemic standards.

The conclusion (9), then, shows that there is no proper reason for an EPist to wish to argue that non-EPists should give up UNIQUENESS. Both kinds of proper reasons (6.i and 6.ii) are blocked by what follows from (1). A s a permissive case, both parties may rationally disagree while sharing the same evidence. This shows an internal tension in the EPist's view. It does not, however, show EP to be false. Rather, it elucidates the fact that once the EPist perspective is adopted, there should come a point when EPists stop wanting to convince their opponents to give up their views. It is difficult to say what point that is, however. I presume it's the point at which all of the available evidence for and against EP has been offered for consideration. If one party becomes aware of new evidence, then by definition EP is no longer a permissive case, and the disagreeing parties would not share $E$. But if all the evidence is on the table, then a consequence of the EPist's view is that they shouldn't wish to continue the debate. 


\section{An Objection}

O ne might ask what it is that E Pists take themselves to be doing when they argue for EP. Perhaps one can reject the conclusion above by suggesting that EPists take themselves to be offering new evidence, in the form of arguments, for EP. A s long as EPists can offer new evidence for EP they might think that, at least temporarily, EP is not permissive. After all, EPists believe that EP is true and UNIQUENESS is false. Even if they acknowledge that UNIQUENESS is rational to believe, being an EPist doesn't preclude one from searching for and offering new evidence to support one's view. Thus, an objector might say that as long as an E Pist is offering new evidence for $E P$, then it is proper for them to want to convince defenders of UNIQUENESS that their view is false, by premise (6.i), and that premise (7) needs some kind of further qualification.

I do not think that this response eliminates the tension in the EPist's position, for two reasons. First, it has unacceptable implications for the "stability" of permissive cases. According to the reasoning above, a hypothesis could become permissive and non-permissive within the context of a single conversation. For example, take the case of two paleontologists, in the same department who have differing views about what killed the dinosaurs. One day over lunch paleontologist A argues for his position with paleontologist $B$. He might go about this in one of two ways. If, for example, A brings to light some previously unknown archeological finding relevant to the dinosaur's extinction, it would be a clear case of offering further evidence. B efore A introduced the new evidence, the case would not be permissive (by definition) because both $A$ and $B$ would not have shared the same evidence. Knowing this, A would have a good reason to wish to argue. But if A simply argues that $B$ 's reasoning about the issue has been mistaken, then $A$ is criticizing the rationality of $B$ 's position.

The objection above suggests that this second way of arguing may itself be a way of introducing new evidence. If that were true, then permissive cases would cease to become permissive every time two parties argued over them. The body of evidence would always be in flux. Permissive cases would only be stable in silence. If each individual discussion between disagreeing parties amounted to new evidence, then permissive cases would cease to be permissive each time there is a spoken disagreement. But this is not what E Pists wish to argue. It is very unlikely that any of us would ever have the same evidence if one includes every possible argument that could be used to interpret the evidence as evidence itself.

We can see, then, that EPists need to make a distinction between 
evidence and arguments that interpret evidence. A rguments that interpret evidence are the embodiment of a person's epistemic standards; these arguments manifest those standards. If EPists refused to make this kind of distinction, then most disagreements (in supposed permissive case) could be explained away by subjects simply having different evidential sets. The permissivist thesis would have very little application. ${ }^{7}$ That is not to say that all evidence must be empirical. Necessary truths, proven axioms of mathematics, rules of logic, etc. could all serve as evidence for certain kinds of propositions. But arguments which are primarily interpretive of evidence are best conceived (from the EPist point of view) as embodying (or establishing) epistemic standards, not themselves as pieces of evidence. Otherwise permissive cases will be rare.

So what kind of evidence is there for EP? EP is not supposed to be an a priori argument. ${ }^{8}$ The primary evidence for EP lies in the apparent cases of reasonable disagreement that we observe. In those cases it seems (to EPists) that people have the same evidence and adopt different yet rational doxastic attitudes towards the evidence: cases involving juries, scientists, politicians, and philosophers. Without such cases there would be no evidence for EP. A nd if the distinction betw een evidence and arguments in the paragraph above holds, then EPists who argue that such cases should be interpreted as support for EP are in effect arguing against the rationality of the UNIQUENESS view. They are arguing against the epistemic standards that defenders of UNIQUENESS use to interpret this same evidence. Thus EPists are really adopting the UNIQUENESS perspective when they argue for their own view, even though it is inconsistent to do so.

\section{Conclusion}

I have argued that EPists should consider the EP debate to be a permissive case. A s such, they should accept UNIQUENESS as an equally rational view, and they should not wish to convince defenders of UNIQUENESS to give up their views on the basis of its rationality. If EPists want to be consistent and continue to argue for EP, then they need to bring forth new relevant evidence. However, EPists must be careful what they qualify as "new evidence." If just any rational argument is considered to be new evidence, then there will be little reason to think that people share the same evidential sets in this and other purportedly permissive cases. Very few people are in possession of all the same arguments and lines of reasoning, although they may be in possession of the same evidence. If EPists admit in too many ways that people can have different evidence, then many of the purported examples of permissive cases will need to be thrown out. In terms of the EP debate, I am doubtful that there is much new evidence 
to be discovered. Cases of apparent rational disagreement seem to be the only evidence available. The arguments then turn on the most rational way to interpret that evidence. If this is correct - and if EPists wish to take their own view seriously - then they probably should stop trying to convince defenders of UNIQUENESS to give up their views.

\section{Notes}

1 As Schoenfield (2014) emphasizes, this does not mean that there is one set of epistemic standards that would permit rational belief in $p$ and $\sim p$ given the same evidence. Rather, we must understand this possibility as the result of $S$ and $S^{*}$ possessing different sets of epistemic standards, each of which are rational.

2 This unique attitude may be understood as belief, disbelief, and suspension of judgement (Feldman, 2007) or in terms of degrees of belief or subjective probabilities (White, 2005; Schoenfield, 2014; and others). For the purposes of this paper I will assume Feldman's tripartite model because the relation between outright belief and degrees of belief is controversial and would be distracting for the purposes of this paper.

3 Philosophers who defend UNIQUENESS deny this second possibility. UNIQUENESS theorists are committed to explaining the current disagreement over EP by saying either that (i) philosophers do not in fact have $E$ with respect to $E P$, or that (ii) given $E, E P$ is not a rational view to hold.

4 Of course the "permissiveness" of the case would need to be bounded in scope to include only those philosophers who are actually participating in the debate and to whom it would be reasonable to suppose have the same evidence. One might imagine this group to include those currently up to speed with the relevant literature.

5 I am assuming that EPists do think it is possible to know when one is in a permissive case. If from a first person perspective it is impossible to recognize when one is in a permissive case, then it would be impossible for EPists to recognize whether the EP debate is a permissive case. But I take it that this is not what most EPists wish to argue. Recognition of permissive cases should not be limited to the third-person point of view. However, this third-person point of view strategy has been offered as one way to get around certain objections posed to EP. See B rueckner and Bundy (2011).

6 This can be seen in the kinds of arguments defenders of UNIQUENESS make against EP. Their arguments focus on the proper or rational way to think about evidence generally (for example, Sosa, Feldman, and M atheson) and/or the non-rational entailments of EP (a.k.a W hite's "arbitrariness objection").

7 This importance of making this distinction can also be seen in the case of jury outcomes. Imagine eight jury members who have all heard the court's evidence and deliberated. They individually write their votes on a piece of paper. Now, if it turns out that half of the jury members vote guilty and the other half not-guilty, there is a stalemate. A ssuming EP is true, it is reasonable to think that 
verdicts of both guilty and not-guilty can be arrived at rationally. (Especially since the vote is split. If the vote were 7-1, we might suspect that one person's decision was perhaps irrational.) All jury members have the same evidence. At this point, an EPist should not wish to convince her fellow jury members to change their vote. To make further arguments would not be to offer new evidence; rather, it would be to challenge the rationality of those who interpret the evidence in a way differently from one's own interpretation. But only a defender of UNIQUENESS can be consistent with her view and wish to convince the others that they are seeing the evidence incorrectly. Only a defender of UNIQUENESS can consistently maintain that disagreeing jury members have incorrectly applied epistemic standards (or used irrational ones) and maintain that there is only one rational way to respond to the court's evidence.

8 It does not seem the EP hypothesis could be established a priori. M ost people in isolation would not, after carefully considering the evidence, reason to $p$ and then think that $\sim p$ is equally rational. People only operate within their own set of epistemic standards. The recognition of the possibility of EP (if there is such) can come only after inferring the EP hypothesis from apparent cases of rational disagreement.

\section{Works Cited}

Brueckner, A nthony and A lex Bundy. (2012) On 'Epistemic Permissiveness.' Synthese 188(2): 165-177.

Christensen, David. (2010) Higher Order Evidence. Philosophy and Phenomenological Research 81(1): 185-215.

Douven, Igor. (2009) Uniqueness Revisited. American Philosophical Quarterly 46(4): 347-361.

Feldman, Richard. (2007) Reasonable Religious Disagreements. In L. A ntony (ed.), P hilosophers without Gods: Meditations on Atheism and the Secular Life (pp. 194-214). N ew York: Oxford University Press.

- - . (2009) Evidentialism, Higher-Order Evidence, and Disagreement. Episteme 6(3): 294-312.

Matheson, Jonathan. (2011) The Case for Rational Uniqueness. Logos and E pisteme 2(3): 359-373.

Rosen, Gideon. (2001) Nominalism, Naturalism, Epistemic Relativism. Philosophical Perspectives 35(15): 69-91.

Schoenfield, Miriam. (2014) Permission to Believe: Why Permissivism Is True and What It Tells Us About Irrelevant Influences on Belief. Nous 48(2): 193-218.

Van Fraassen, Bas. (2002) The E mpirical Stance. New Haven: Yale U niversity Press.

White, Roger. (2005) Epistemic Permissiveness. Philosophical Perspectives 19(1): 445-459. 